\title{
Power consumption modeling in optical multilayer networks
}

\author{
Ward Van Heddeghem, Filip Idzikowski ${ }^{*}$, Willem Vereecken, Didier Colle, Mario Pickavet, Piet Demeester \\ Department of Information Technology (INTEC) of Ghent University - IBBT, \\ Gaston Crommenlaan 8, B-9050 Gent, Belgium, tel: +32(0)9 3314 977, fax: +32(0)93314899 \\ Email address: ward.vanheddeghem@intec.ugent.be (Ward Van Heddeghem) \\ "Department Telecommunication Systems (TKN) of Technical University of Berlin, \\ Einsteinufer 25, 10587 Berlin, Germany
}

\begin{abstract}
The evaluation and reduction of energy consumption of backbone telecommunication networks has been a popular subject of academic research for the last decade. A critical parameter in these studies is the power consumption of the individual network devices. It appears that across different studies, a wide range of power values for similar equipment is used. This is a result of the scattered and limited availability of power values for optical multilayer network equipment. We propose reference power consumption values for Internet protocol/multiprotocol label switching (IP/MPLS), Ethernet, optical transport networking (OTN) and wavelength division multiplexing (WDM) equipment. In addition we present a simplified analytical power consumption model that can be used for large networks where simulation is computationally expensive or unfeasible. For illustration and evaluation purpose, we apply both calculation approaches to a case study, which includes an optical bypass scenario. Our results show that the analytical model approximates the simulation result to over $90 \%$ or higher, and that optical bypass potentially can save up to $50 \%$ of power over a non-bypass scenario.
\end{abstract}

Keywords - Green ICT, energy-efficiency, power consumption, core networks, optical networks, DWDM

\section{INTRODUCTION}

There is a growing number of publications on network power consumption - It can be argued that interest and research into power consumption of Information and Communications Technology (ICT) networks started in 2003 with the paper "Greening of the Internet" by Gupta and Singh [1]. At that time "Green Networking" was still referred to as a "somewhat controversial subject". The paper discusses the power consumption of network devices and, on a larger scale, the Internet, and proposes a number of approaches to increase its energy-efficiency. Since then, numerous related papers have been published and presented. Most of these publications either provide an estimate of the current and future power consumption of (some subset of) networks, or evaluate a proposed solution for their power-saving potential. The main drivers for power reduction research are usually economical (reducing the energy cost), technical (reducing the associated heat dissipation) and environmental (reducing the carbon footprint) reasons.
Correct equipment power consumption values are key input for power evaluation studies - All of the above purposes boil down to power consumption estimations, and one of the key inputs is the power consumption values of the constituting components. Sufficiently correct absolute power values are important for policy makers to assess the importance of ICT power consumption in comparison to other sectors. For example, if ICT networks consume relatively little power, it makes sense to focus research on using ICT networks to achieve energy savings in other domains. This is sometimes referred to as 'greening by ICT' and is the driver behind the frequently cited Smart 2020 report [2]. Sufficiently correct relative values of network equipment are important to network equipment vendors and researchers in order to focus on solutions with the largest overall saving potential. For example, as long as optical line amplifiers constitute less than 3 percent of the total power consumption of a core network [3], there is little reason to focus research on making them more energy-efficient.

Currently used equipment power values suffer from a number of issues - However, the power consumption values assumed in many papers suffer from a number of issues. First, they can differ substantially between publications. For example, while an optical amplifier is taken to consume $0.5 \mathrm{~W}$ per channel in [3] (the authors report $8 \mathrm{~W}$ per fiber, with a fiber carrying 16 channels), $1000 \mathrm{~W}$ per channel is assumed in [4]. This is more than three orders of magnitude difference. Second, one single device is often used as a source for the associated equipment power consumption, without being clear whether it is representative or not. In a few cases, no source is mentioned. Third, it is not always clear whether the power value used is just for the core functionality of the equipment, or whether it also takes into account any required control and support equipment like control cards and chassis power consumption. In addition, maximum power consumption values are sometimes used, which can differ substantially from power consumption under typical operating conditions.

To calculate total power consumption, simulation is not always practical - The approach often used to estimate the total power consumption of a network with a given admissible topology fed with a certain traffic matrix, is based on dimensioning the network through simulation. 
Dimensioning entails determining the capacity requirements of all equipment. Simplifying the problem, dimensioning can be done by for example shortest-path routing all the traffic through the network. As a result of the dimensioning process all equipment counts (routers, router ports, transponders, etc.) are known. By multiplying the equipment count with the corresponding equipment power consumption the total network power consumption can be calculated. However, for large networks (in terms of nodes and links) this becomes computationally expensive. In addition, this approach does not give an indication upfront about the power consumption share of certain equipment and layers to the total result.

\section{Contributions of this paper}

In this paper we address the issues outlined above for optical multilayer network. As such, the contributions of this paper are the following:

- we provide reference values for each equipment type, complete with direct source references where possible the values are mostly based on public product data sheets (section 3),

- $\quad$ we deduce a simplified analytical power model based on IP demands and the IP-layer hop count, that can be used as an alternative to dimensioning the network through simulation (section 4),

- finally, in section 5, we illustrate and evaluate with a case study how to use the information in this paper to determine the power consumption of an IP-over-WDM network, both via simulation and using the analytical model.

Due to space limitations, the individual reference values and detailed discussions are available as a separate report [5].

\section{RELATED WORK}

We surveyed research articles that tackle cost models of multilayer networks. We looked at component-based and analytical power models, but considered also non-power consumption cost models.

Non-power consumption publications we build upon - In [6], a capital expenditures (CapEx) model is given for optical multilayer networks, subdividing the network in four layers: Internet protocol/multiprotocol label switching (IP/MPLS), Ethernet, synchronous digital hierarchy/optical transport network (SDH/OTN) and wavelength division multiplexing (WDM). Detailed normalized monetary cost values of equipment in each layer are listed in this paper. We use this model as a basis for our equipment categorization, updated to reflect recent changes and expected future evolutions. In [7], a so-called "network global expectation model" is presented. The model proposes a number of equations to calculate expected values of network properties - such as the average node degree, the average number of hops, or the number of ports and capacity of a cross-connect - based on a few primary network properties. This approach is the idea behind the analytical power model we propose in section 4 .

Component-based power models - Most of the publications evaluating solutions to increase energy-efficiency consider a power consumption model based on the individual power consumption of a few components and somehow counting the occurrence of each component (for example via a network dimensioning tool or integer linear programming (ILP) approach). We provide a short selection of such publications here. In [3], the power saving possibility of static optical bypass over non-bypassed design in an IP over WDM network is investigated. The power consumption model considers IP router ports, transponders and optical amplifiers. In our related work on optical bypass [8], we assumed transponders to be part of the router interfaces, and additionally considered $3 \mathrm{R}$ regenerators. In [9], where optical cross connects are inserted between optoelectronic devices and the router in order to reduce power consumed in the network. Optical cross-connects (OXCs) and SONET/SDH devices are taken into account in addition to router ports, transponders and optical amplifiers. In [4], the energy-saving potential of turning off spare devices in an IP backbone network is investigated. The power model used is based on fixed-size core nodes with constant and equal power consumption and link power consumption (which is itself based on the inline amplifiers and the corresponding static power consumption of the router interface) scaling with the number of channels. In [10], Chabarek et.al. measured the power consumption of two Cisco routers at different line card filling configurations. They devised a power consumption model from these observations that is the sum of the power consumption of the chassis and the installed active line cards (load dependent).

Analytical power models — The following two works take a slightly different approach as they try to estimate the total power consumption rather than evaluate a specific solution for energy-efficiency. They calculate the total network power consumption directly, based on the average hop count and power efficiency values for the involved equipment. Additional factors account for traffic protection, future provision and cooling power overhead. In [11], Baliga, Tucker et al. propose a power consumption per customer model for optical networks, considering all main subnetworks such as access, metro and core. The power consumption in the core nodes is based on the power consumption efficiency of a typical core router. The link power consumption considers a channel efficiency value based on a typical WDM terminal system and inline amplifiers, differentiating between terrestrial and undersea links. In [12], a generalization of the model used in [11] is proposed, and referred to as a "transaction-based model". It is almost identical to the analytical power model we propose in section 4, the main difference being that we consider a slightly different equipment breakdown and hop count attribution. 
Other similar work - The technical report by Idzikowski [13] provides an extensive list of power consumption values of various network elements of IP over WDM networks, based on product data sheets and research papers. The report categorizes the equipment in IP layer equipment and WDM layer equipment. The main difference with our work is that it does not homogenize the reported values based on for example functionality or capacity. In contrast, [14] uses a bottom-up approach to estimate the power consumption of high-capacity IP routers. It is based on aggregating the individual power consumption of the constituting parts such as transceivers, fabric interfaces and packet buffers. Different from our work, it is only focused on the nodes, rather than all network components. Power efficiency values are also given in [15], where a detailed analysis is done of various network element types (e.g., IP routers, Ethernet switches, SDH switches) and their functional components (framing, amplification, routing, etc.) with respect to power dissipation. However, in contrast to our work, it does not provide tractable references, and it does not include a power model.

\section{REFERENCE POWER CONSUMPTION VALUES}

In this section we provide power consumption reference values for common IP over WDM equipment. These reference values are mostly based on publicly available product data sheets. Due to space restrictions, references to these source documents and associated detailed discussion for each equipment type are not given here. They are available in [5].

To provide consistent power consumption values, we provide:

- typical values, i.e., under typical load and conditions, rather than maximum power consumption values; please note that any derived efficiency values [W/Gbps] are calculated with respect to the capacity of the relevant equipment and not the actual throughput, which could be (far) less,

- $\quad$ values that include chassis and control overhead power consumption; external cooling or facilities overhead (lighting, etc.) is not included,

- $\quad$ values for bidirectional equipment (i.e. full-duplex)

Building on the CapEx work presented in [6], we consider the multilayer network and associated equipment to be subdivided in the following four layers:

- $\quad$ an IP/MPLS layer with associated routers which perform layer 3 switching,

- an Ethernet layer, which performs layer 2 switching,

- an OTN layer, which performs layer 1 time division multiplexing and transmission and adds monitoring,

- a WDM layer, which performs layer 1 space division multiplexing and transmission.

\subsection{IP/MPLS layer}

The IP/MPLS power consumption is based on publicly available data sheet values of two major commercial core routers: the Cisco CRS series and the Juniper T-series. More specifically, we will base the model on the values of the CRS3 series, since it is the most recent architecture and most energy-efficient one (see Fig. 3).

Following the convention in [6], the equipment in the IP/MPLS layer consists of three building blocks (see Fig. 1). The basic node (e.g., a 1280 Gbps router) contains the chassis, switch fabric, routing engine, power supply, internal cooling and remaining minor components. The basic node contains slot cards (e.g., a 40 Gbps slot card), which contain one or more modules that can each hold a port card (e.g., a $4 \times 10$ GE port card). The main functional block in the slot cards is the forwarding engine. The port card mainly contains the layer-2/3 interface and physical connection (such as PoS STM-256, or 10 Gigabit Ethernet).

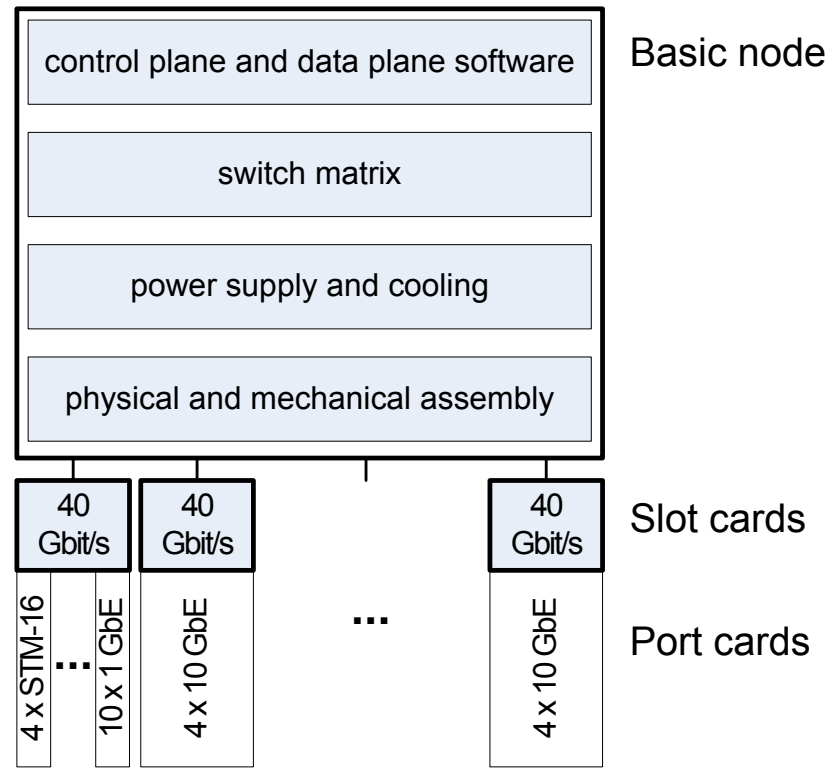

Fig. 1 Simplified IP/MPLS router block model (from [6])

This breakdown is representative for the power consumption of an IP/MPLS node. Fig. 2 shows the power distribution of five maximum core router configurations. The slot and port card combined make up roughly $75 \%$ of the power consumption. Power supply and internal cooling accounts for $10 \%$ (the CRS-3 value is lower because it does not include the power supply, which could not specifically be attributed to). Finally, the chassis is roughly $15 \%$, mainly attributed to the switch fabric (about $10 \%$ of the total). 


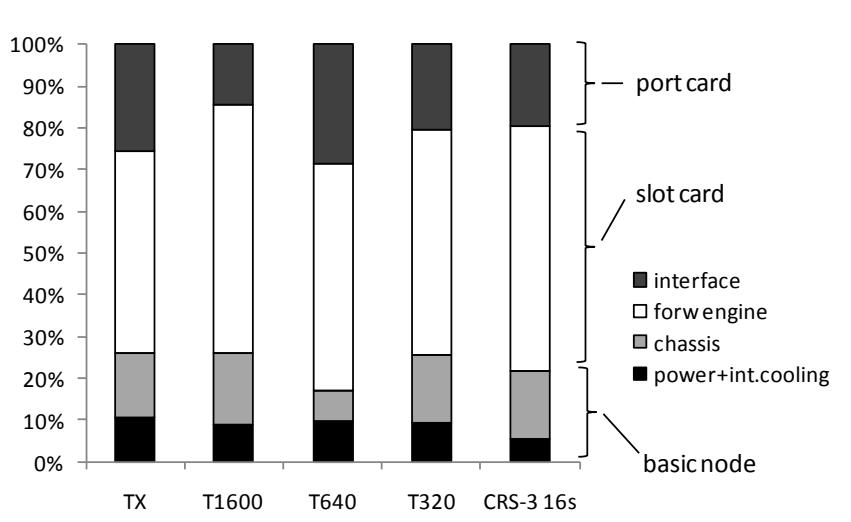

Fig. 2 Core router power distribution among the different components

Table 1 lists the power consumption values for the various components, based on the CRS-3 router. The basic node building blocks consist of 16-slot line card shelves (LCSs) and optionally fabric card shelves (FCSs). The fabric card shelf can connect up to 9 line card shelves, and a configuration with maximum 8 fabric card shelves (and thus 72 line card shelves) is possible. The table lists both these two building blocks, as well as a few intermediate configurations.

Table 1 IP/MPLS components

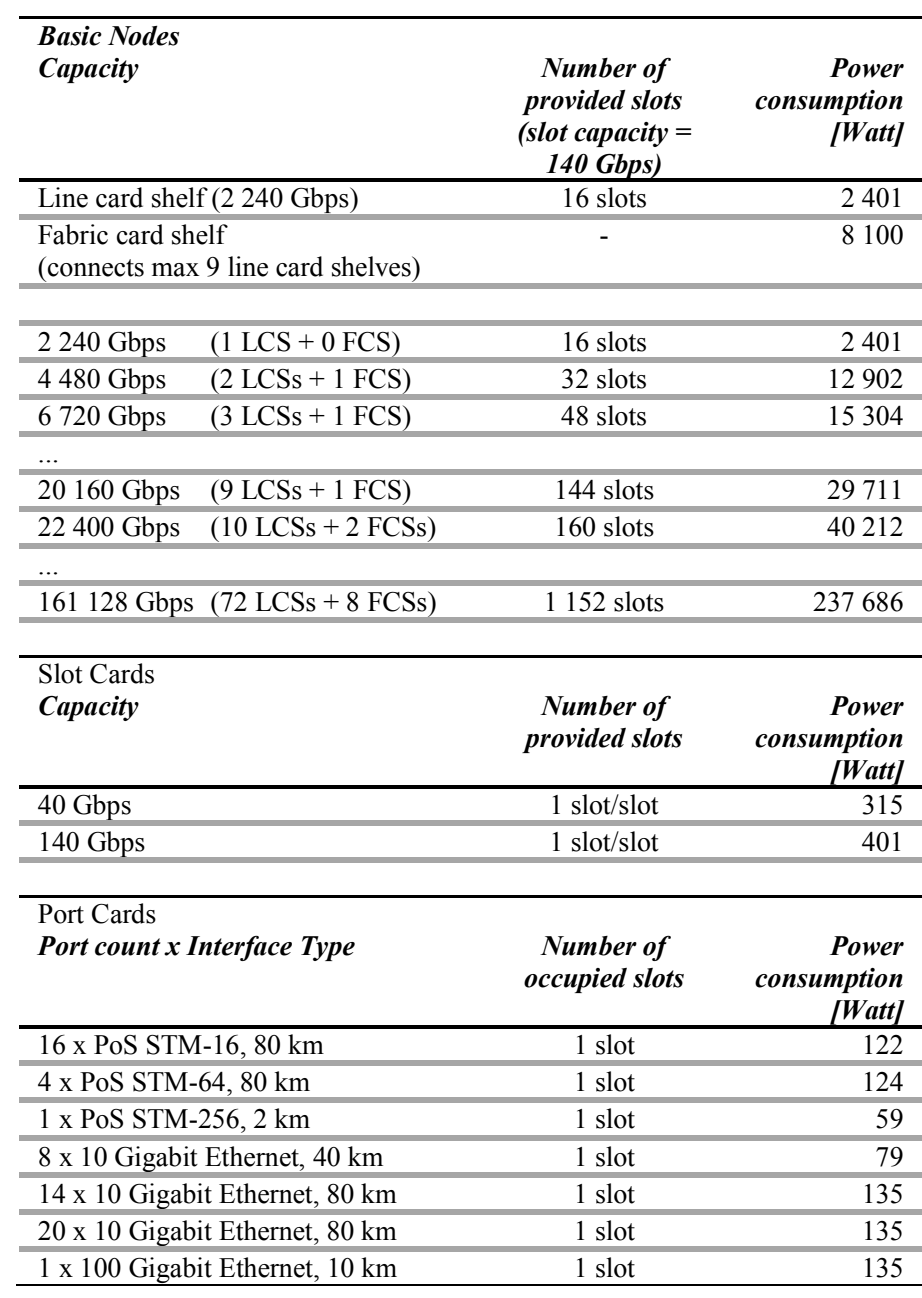

Fig. 3 Core router power consumption as a function of the total node capacity, for maximally equipped configurations (full CRS range not shown; all CRS configurations are based on 16-slot CRSs).

Based on the values shown in Fig. 3, we additionally propose a simplified IP/MPLS layer power value that expresses the power $\mathrm{P}_{\mathrm{IP}}$ of the node based on the total node capacity $\mathrm{C}_{\mathrm{IP}}$ :

$\mathrm{P}_{\mathrm{IP}} / \mathrm{C}_{\mathrm{IP}}=10 \mathrm{~W} / \mathrm{Gbps}$

This value is higher than the current achievable CRS-3 energy-efficiency (5.5-7.5 W/Gbps), but seems more reasonable as it implicitly covers sub-optimally filled configurations. It is important to note that this value expresses a power efficiency per equipment capacity. The actual value might be, and will be, higher (i.e. worse) for real life throughputs where the average throughput will be lower than the capacity.

Fixed power-per-port values can be derived from the powerper-node-capacity value given above. For example, a 10G port would consume $100 \mathrm{~W}$.

\subsection{Ethernet Layer}

The Ethernet power consumption is based on two systems: the Cisco Nexus 7018 and the Juniper EX8216. The power consumption values are based on the typical power consumption of a maximum configured system, including the power overhead of the chassis and any required control and switch fabric cards.

The values are given in Table 2. Power values between brackets represent a projection to higher capacities based on the exponential function for $1 \mathrm{Gbps}$ and $10 \mathrm{Gbps}$ ports. 
Table 2 Ethernet layer (bidirectional)

\begin{tabular}{lll}
\hline Type & $\begin{array}{l}\text { Power consumption } \\
\text { [Watt] }\end{array}$ & $\begin{array}{l}\text { Power efficiency } \\
\text { [Watt/Gbps] }\end{array}$ \\
\hline Ethernet 1 Gbps port & $7 \mathrm{~W}$ & $7 \mathrm{~W} / \mathrm{Gbps}$ \\
\hline Ethernet 10 Gbps port & $38 \mathrm{~W}$ & $3.8 \mathrm{~W} / \mathrm{Gbps}$ \\
\hline Ethernet 40 Gbps port & $(105 \mathrm{~W})$ & $(2.6 \mathrm{~W} / \mathrm{Gbps})$ \\
\hline Ethernet 100 Gbps port & $(205 \mathrm{~W})$ & $(2.1 \mathrm{~W} / \mathrm{Gbps})$ \\
\hline Ethernet 400 Gbps port & $(560 \mathrm{~W})$ & $(1.4 \mathrm{~W} / \mathrm{Gbps})$ \\
\hline Ethernet 1 Tbps port & $(1100 \mathrm{~W})$ & $(1.1 \mathrm{~W} / \mathrm{Gbps})$ \\
\hline
\end{tabular}

\subsection{OTN layer}

The OTN power consumption is based on confidential information and are approximations. The power consumption values are based on the typical power consumption of a maximum configured system, including the power overhead of the chassis and any required control and switch fabric cards.

The values are given in Table 3. Power values between brackets represent a projection to higher capacities based on the exponential function for $40 \mathrm{Gbps}$ and $100 \mathrm{Gbps}$ ports. It is interesting to observe that the power efficiency becomes worse at $40 \mathrm{Gbps}$. This is probably due to heavy digital signal processing, which is not present in the lower-capacity cards.

Table 3 OTN layer (bidirectional)

\begin{tabular}{lll}
\hline Type & $\begin{array}{l}\text { Power consumption } \\
\text { [Watt] }\end{array}$ & $\begin{array}{l}\text { Power Efficiency } \\
\text { [Watt/Gbps] }\end{array}$ \\
\hline OTN 1 Gbps port & $7 \mathrm{~W}$ & $7 \mathrm{~W} / \mathrm{Gbps}$ \\
\hline OTN 2.5 Gbps port & $15 \mathrm{~W}$ & $6 \mathrm{~W} / \mathrm{Gbps}$ \\
\hline OTN 10 Gbps port & $34 \mathrm{~W}$ & $3.4 \mathrm{~W} / \mathrm{Gbps}$ \\
\hline OTN 40 Gbps port & $160 \mathrm{~W}$ & $4 \mathrm{~W} / \mathrm{Gbps}$ \\
\hline OTN 100 Gbps port & $360 \mathrm{~W}$ & $3.6 \mathrm{~W} / \mathrm{Gbps}$ \\
\hline OTN 400 Gbps port & $(1236 \mathrm{~W})$ & $(3.09 \mathrm{~W} / \mathrm{Gbps})$ \\
\hline OTN 1 Tbps port & $(2794 \mathrm{~W})$ & $(2.79 \mathrm{~W} / \mathrm{Gbps})$ \\
\hline
\end{tabular}

\subsection{WDM layer}

WDM component terminology and their associated functions can differ considerably between different vendor and academic documents. To avoid misunderstanding, we first give an overview of the main terminology of the WDM components in this paper. For a more detailed explanation, see [6] or [16].

Transceivers provide full-duplex conversion from/to an electrical signal to/from an optical signal. They are typically commercially available in standardized enclosures such as SFP (1G) and XFP (10G), XENPAK (10G), CFP (100G) ${ }^{1}$. The power consumption of transceivers is usually provided by the power budget of the port card. Therefore, we do not consider individual power consumption of transceivers. Transponders are devices that provide bidirectional conversion from one optical wavelength to another, typically from/to a grey $(1300 \mathrm{~nm})$ optical signal to a DWDM-band $(1500 \mathrm{~nm})$ specific wavelength optical signal. Transponders

\footnotetext{
${ }^{1}$ SFP: small form factor pluggable, XFP: 10 Gigabit Small Form Factor Pluggable, XENPAK, CFP: C form-factor pluggable
}

can be considered as two back-to-back transceivers. The (grey) client side interface typically has limited reach (e.g. up to $2 \mathrm{~km}, 40 \mathrm{~km}$, or $80 \mathrm{~km}$ ), whereas the line side interface typically has longer reach (e.g. $200 \mathrm{~km}, 500 \mathrm{~km}$ or $2000 \mathrm{~km}$ ) given the appropriate amplification (see further). Muxponders are similar devices and come typically in an electrical-optical and optical-optical variant. They perform full-duplex timedivision multiplexing of lower rate tributary signals into higher rate WDM signals. We treat transponders and opticalto-optical muxponders as one component, since their power consumption (and functionality) is similar for same-rate equipment. Regenerators provide 3R (re-timing, re-shaping, re-transmitting) regeneration of optical signals. The distance the signal can travel (span) before regeneration is required depends on the transponder type, data rate, modulation used, fiber quality, etc. A regenerator can be considered as two back-to-back transponders, and is in practice often implemented as such.

Optical line amplifiers (OLAs) cater for signal attenuation and are required at a typical interval of $80 \mathrm{~km}$. An OLA system includes an optical amplifier (erbium-doped fiber amplifier (EDFA) or Raman) per fiber and some additional electronics. OLAs are typically unidirectional, however, as all the values in this report are for bidirectional solutions, we give power consumption for bidirectional OLAs that in practice will be composed of two unidirectional OLAs. WDM terminal systems, also called WDM (transmission) systems, (de)multiplexes the individual channels (from) into the fiber pair. They consist of a mux/demux, a booster amplifier (to amplify the outgoing optical signal) and a pre-amplifier (to amplify the incoming optical signal). The WDM terminal is mainly characterized by the number of supported WDM channels (e.g., 40, 80, 96).

Optical switches perform switching of wavelength channels without the need for OEO conversion. OADMs (optical adddrop multiplexers) provide two bidirectional transit fiber ports and are capable of adding-dropping individual wavelengths to a local port. OADMs are characterized by (a) the passthrough capacity at 40 or 80 channels, (b) the percentage of channels that can be added, and (c) the reconfigurability (ROADMs). OXCs (optical cross connects) provide more than two bidirectional fiber ports and are capable of crossconnecting wavelength channels. In line with the terminology used in [6], the number of network-side bidirectional fiber ports of an OXC is known as the degree. This does not include the add/drop fiber ports which we label as the add/drop degree.

For degree-2 nodes, ROADMs can be used, for multi-degree switching OXCs are used (which can be implemented in practice by combining a number of ROADMs). Different technologies can be used for implementing optical switches, e.g., microelectromechanical systems (MEMS) or liquid crystal-based wavelength selective switches. Unfortunately, the underlying technology was unclear for the provided values. It is probably MEMS though. 
Dynamic gain equalizers (DGEs) and dispersioncompensating fibers (DCFs), which provide signal conditioning, are not considered. They are either passive devices with negligible indirect power consumption impact on the other components, or consume negligible power.

The values listed in Table 4 are the proposed values for the various WDM components. These values are based on a generalization of data sheet power consumption values of a wide number of components [5]. The values between brackets indicate projected values. Node degree $d$ is the number of network-side bidirectional fiber ports. The add/drop degree $a$ is the number of add/drop bidirectional fiber ports, potentially ranging from 0 to $d$. Note that the transponder values provided in Table 4 are for non-coherent transponders. Values for coherent transponders will be higher, but no public values are available yet. Coherent transponders are used to increase the transmission distance at higher bandwidths.

Table 4 WDM components (bidirectional)

\begin{tabular}{|c|c|c|}
\hline Type & Remarks & $\begin{array}{r}\text { Power consumption } \\
\text { [Watt] }\end{array}$ \\
\hline Transponder/Muxponder 2.5G & \multirow{6}{*}{$\begin{array}{l}\text { Per channel pair, } \\
\text { includes overhead. } \\
\text { All non-coherent } \\
\text { transponders. }\end{array}$} & $25 \mathrm{~W}$ \\
\hline Transponder/Muxponder 10G & & $50 \mathrm{~W}$ \\
\hline Transponder/Muxponder 40G & & $100 \mathrm{~W}$ \\
\hline Transponder/Muxponder 100G & & $(150 \mathrm{~W})$ \\
\hline Transponder/Muxponder 400G & & $(300 \mathrm{~W})$ \\
\hline Transponder/Muxponder 1T & & $(500 \mathrm{~W})$ \\
\hline Regenerator $\mathrm{xG}$ & $\begin{array}{l}\text { Per channel pair, } \\
\text { includes overhead }\end{array}$ & $2 \cdot \operatorname{transponder} \mathrm{xG}$ \\
\hline OLA, short span $2 \mathrm{~km}$ & \multirow{4}{*}{$\begin{array}{l}\text { Per fiber pair (!), } \\
\text { includes overhead }\end{array}$} & $65 \mathrm{~W}$ \\
\hline OLA, medium span $40 \mathrm{~km}$ & & $65 \mathrm{~W}$ \\
\hline OLA, long span 80 km & & $110 \mathrm{~W}$ \\
\hline OLA, very long span $120 \mathrm{~km}$ & & $120 \mathrm{~W}$ \\
\hline WDM terminal, 40 channels & \multirow[b]{2}{*}{$\begin{array}{l}\text { Per fiber pair, } \\
\text { includes } \\
\text { mux/demux, pre- } \\
\text { and booster } \\
\text { amplifier, and } \\
\text { overhead }\end{array}$} & $230 \mathrm{~W}$ \\
\hline WDM terminal, 80 channels & & $240 \mathrm{~W}$ \\
\hline ROADM, 40 channels, $100 \%$ & \multirow{3}{*}{$\begin{array}{l}\text { Per node, includes } \\
\text { mux/demux, pre- } \\
\text { and booster } \\
\text { amplifier, and } \\
\text { overhead }\end{array}$} & $450 \mathrm{~W}$ \\
\hline ROADM, 80 channels, $50 \%$ & & $550 \mathrm{~W}$ \\
\hline ROADM, 80 channels, $100 \%$ & & $600 \mathrm{~W}$ \\
\hline $\begin{array}{l}\text { OXC, } 40 \text { channels } \\
\text { node degree } d \text {, } \\
\text { add/drop degree } a\end{array}$ & \multirow{2}{*}{$\begin{array}{l}\text { Per node, } \\
\text { includes, } \\
\text { mux/demux (for } \\
\text { add/drop), pre- } \\
\text { and booster } \\
\text { amplifier, and } \\
\text { overhead }\end{array}$} & $\begin{aligned} \mathrm{d} \cdot 85 \mathrm{~W}+\mathrm{a} \cdot 50 \mathrm{~W} \\
+150 \mathrm{~W}\end{aligned}$ \\
\hline $\begin{array}{l}\text { OXC, } 80 \text { channels } \\
\text { node degree } d \text {, } \\
\text { add/drop degree } a\end{array}$ & & $\begin{array}{r}d \cdot 85 W+a \\
100 W+150 W\end{array}$ \\
\hline
\end{tabular}

\section{ANALYTICAL POWER CONSUMPTION MODEL}

In this section we propose a simplified analytical power consumption model for the various layers. The model is given first (section 4.1). The details on how the model is constructed follow (section 4.2).

\subsection{Model}

The total power $P_{\text {core }}$ [Watt] in an optical multilayer core network is the sum of the power consumption in the constituting layers:

$P_{\text {core }}=P_{i p}+P_{\text {ethernet }}+P_{\text {otn }}+P_{w d m}$

with

$P_{w d m}=P_{o p t s w}+P_{\text {transpondes }}+P_{\text {amplifiers }}+P_{\text {regeneraton }}$

The power consumption for each layer can be written as a function of the average IP demand $\overline{D_{C}}$, a power efficiency $\mathrm{P} / \mathrm{C}$ value for that layer, and the hop count $H$ for each layer:

$$
\begin{aligned}
P_{i p} & =\eta_{c} \cdot \eta_{p r} \cdot N_{d} \cdot \overline{D_{C}} \cdot\left[\frac{P_{I P}}{C_{I P}} \cdot 2 \cdot\left(\frac{1}{\eta_{p r}}+H\right)\right] \\
P_{\text {ethernet }} & =\eta_{c} \cdot \eta_{p r} \cdot N_{d} \cdot \overline{D_{C}} \cdot\left[\frac{P_{E T H}}{C_{E T H}} \cdot 2 \cdot\left(\frac{1}{\eta_{p r}}+H\right)\right] \\
P_{\text {otn }} & =\eta_{c} \cdot \eta_{p r} \cdot N_{d} \cdot \overline{D_{C}} \cdot\left[\frac{P_{\text {OTN }}}{C_{O T N}} \cdot 2 \cdot\left(\frac{1}{\eta_{p r}}+H\right)\right] \\
P_{\text {optsw }} & =\eta_{c} \cdot \eta_{p r} \cdot N_{d} \cdot \overline{D_{C}} \cdot\left[\frac{P_{O X C}}{C_{O X C}} \cdot 2 \cdot H\right] \\
P_{\text {transpondes }} & =\eta_{c} \cdot \eta_{p r} \cdot N_{d} \cdot \overline{D_{C}} \cdot\left[\frac{P_{T R}}{C_{T R}} \cdot 2 \cdot H\right] \\
P_{\text {amplifiers }} & =\eta_{c} \cdot \eta_{p r} \cdot N_{d} \cdot \overline{D_{C}} \cdot\left[\frac{1}{f} \frac{P_{O L A}}{C_{O L A}} \cdot\left\lfloor\frac{\alpha}{L_{a m p}}\right] \cdot H\right] \\
P_{\text {regeneraton }} & =\eta_{c} \cdot \eta_{p r} \cdot N_{d} \cdot \overline{D_{C}} \cdot\left[\frac{P_{R E}}{C_{R E}} \cdot\left\lfloor\frac{\alpha}{L_{r e g e n}}\right\rfloor \cdot H\right]
\end{aligned}
$$

The symbols with description and reference values are listed in Table 5 


\begin{tabular}{|c|c|c|c|c|}
\hline Quantity & Symbol & $\begin{array}{l}\text { Value } \\
(2.5 G)\end{array}$ & $\begin{array}{l}\text { Value } \\
\text { (10G) }\end{array}$ & $\begin{array}{c}\text { Value } \\
(100 G)\end{array}$ \\
\hline Efficiency, IP/MPLS core router & $\mathrm{P}_{\mathrm{IP}} / \mathrm{C}_{\mathrm{IP}}$ & $10 \mathrm{~W} / \mathrm{Gbps}$ & $10 \mathrm{~W} / \mathrm{Gbps}$ & $10 \mathrm{~W} / \mathrm{Gbps}$ \\
\hline Efficiency, Ethernet & $\mathrm{P}_{\mathrm{E}} / \mathrm{C}_{\mathrm{E}}$ & $1.3 \mathrm{~W} / \mathrm{Gbps}$ & $3.8 \mathrm{~W} / \mathrm{Gbps}$ & $2.1 \mathrm{~W} / \mathrm{Gbps}$ \\
\hline Efficiency, OTN & $\mathrm{P}_{\mathrm{OTN}} / \mathrm{C}_{\mathrm{OTN}}$ & $6.0 \mathrm{~W} / \mathrm{Gbps}$ & $3.4 \mathrm{~W} / \mathrm{Gbps}$ & $3.6 \mathrm{~W} / \mathrm{Gbps}$ \\
\hline Efficiency, Optical switching, & $\mathrm{P}_{\mathrm{OXC}} / \mathrm{C}_{\mathrm{OXC}}$ & & & \\
\hline ROADM, $100 \%, 40 \mathrm{ch}$. & & $2.25 \mathrm{~W} / \mathrm{Gbps}$ & $0.56 \mathrm{~W} / \mathrm{Gbps}$ & $0.06 \mathrm{~W} / \mathrm{Gbps}$ \\
\hline $\mathrm{OXC}$, degree $=3,40 \mathrm{ch}$. & & $1.85 \mathrm{~W} / \mathrm{Gbps}$ & $0.46 \mathrm{~W} / \mathrm{Gbps}$ & $0.05 \mathrm{~W} / \mathrm{Gbps}$ \\
\hline Efficiency, transponder & $\mathrm{P}_{\mathrm{TR}} / \mathrm{C}_{\mathrm{TR}}$ & $10 \mathrm{~W} / \mathrm{Gbps}$ & $5 \mathrm{~W} / \mathrm{Gbps}$ & $1.5 \mathrm{~W} / \mathrm{Gbps}$ \\
\hline Efficiency, optical line amplifier, long span (40 ch) & $\mathrm{P}_{\mathrm{OLA}} / \mathrm{C}_{\mathrm{OLA}}$ & $1.1 \mathrm{~W} / \mathrm{Gbps}$ & $0.27 \mathrm{~W} / \mathrm{Gbps}$ & $0.03 \mathrm{~W} / \mathrm{Gbps}$ \\
\hline Efficiency, regenerators & $\mathrm{P}_{\mathrm{RE}} / \mathrm{C}_{\mathrm{RE}}$ & $20 \mathrm{~W} / \mathrm{Gbps}$ & $10 \mathrm{~W} / \mathrm{Gbps}$ & $3 \mathrm{~W} / \mathrm{Gbps}$ \\
\hline Provisioning factor for protection & $\eta_{\mathrm{pr}}$ & \multicolumn{3}{|c|}{2} \\
\hline Provisioning factor for cooling and facilities overhead (=PUE) & $\eta_{\mathrm{c}}$ & \multicolumn{3}{|c|}{2} \\
\hline Average layer hop count & $\mathrm{H}$ & \multirow{3}{*}{\multicolumn{3}{|c|}{$\begin{array}{l}\text { Depends on network topology, traffic demands and routing } \\
\text { Given by the traffic matrix } \\
\text { Given by the traffic matrix }\end{array}$}} \\
\hline Total number of IP/MPLS demands & $\mathrm{N}_{\mathrm{d}}$ & & & \\
\hline Average demand capacity & $\overline{D_{C}}$ & & & \\
\hline Average fiber filling ( $\%$ of used channels in fiber) & $\mathrm{f}$ & \multicolumn{3}{|c|}{$\begin{array}{c}\text { Depends on network topology, traffic demands, established } \\
\text { lightpaths and routing }\end{array}$} \\
\hline Average (lightpath) link length & $\alpha$ & \multicolumn{3}{|c|}{ Given by the network topology } \\
\hline Optical amplification span length & $\mathrm{L}_{\mathrm{amp}}$ & \multicolumn{3}{|c|}{$80 \mathrm{~km}$} \\
\hline Optical regeneration length & $\mathrm{L}_{\text {regen }}$ & \multicolumn{3}{|c|}{$1500 \mathrm{~km}$} \\
\hline
\end{tabular}

Remarks:

- The power efficiency values $P / C$ have been determined by dividing the power values from section 3 by the capacity of the corresponding component. Exemplary values are given for $2.5 \mathrm{G}, 10 \mathrm{G}$ and $100 \mathrm{G}$ equipment.

- The booster and pre-amplifier power consumption is accounted for optical switching instead of the amplifiers, see further.

- The factor $\eta_{c}$ accounts for cooling and facilities overhead power consumption in telecom centers. This overhead is commonly characterized by the power usage effectiveness (PUE) [17]. The PUE is the ratio of the total amount of power consumed over the useful power consumed, and typically has a value of 2 [18]. In highly optimized and efficiently cooled data centers, lower PUE values are possible, but this is not yet commonplace. The subscript $c$ has been chosen to be in line with the terminology used in [12].

- The factor $\eta_{p r}$ accounts for traffic protection, and equals

2 for $1+1$ protection. For unprotected traffic the value would be 1 .

- The average IP/MPLS-layer hop count $H$ is the number of hops in the respective layer averaged over all traffic demands. For a given topology, the hop count will depend on such aspects as the routing algorithm, link weights, etc. For the equations to be valid, each hop in the IP/MPLS layer means the termination of a lightpath.

\subsection{Explanation}

Power consumption in the IP/MPLS layer is calculated according to the number of router ports required for supporting a single bidirectional (i.e., full-duplex) demand with capacity $D_{C}$ between nodes A and B, see Fig. 4 .

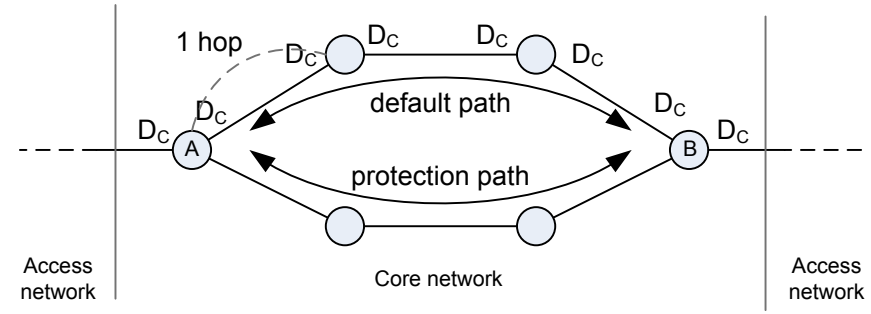

Fig. 4 Required router ports for one $1+1$ protected demand

So, the resulting IP/MPLS capacity $T_{C}$ (in [Gbps]) required for this single demand is given by:

$T_{C}=D_{C}+\eta_{p r}\left(2 \cdot H \cdot D_{C}\right)+D_{C}=2 \cdot D_{C} \cdot\left(1+\eta_{p r} \cdot H\right)$

As we can see, it is a function only of the demand capacity $D_{C}$, the number of routing hops $H$ and the protection factor $\eta_{p r}=2$. Note that we assume the number of hops in the protection path to be equal to the number of hops in the default path.

Thus, if we assume an average demand capacity $\overline{D_{C}}$, the required total IP/MPLS capacity $\mathrm{T}_{\mathrm{IP}}$ (in [Gbps]) is given by multiplying with the total number of demands $N_{d}$ :

$T_{I P}=N_{d} \cdot \overline{T_{C}}$

The power consumption in the IP/MPLS layer $P_{I P}$ is the total capacity $T_{I P}$ multiplied by the bidirectional (or full-duplex) power efficiency $E_{I P}$ of this layer.

The power efficiency $\mathrm{E}_{\mathrm{IP}}$ of the IP/MPLS layer is determined by the power consumption of the router (i.e., basic node equipped with slot and port cards) for a given capacity $(P$ $\left.{ }_{I P} / C_{I P}\right)$ and any additional external overhead power, indicated by the factor $\eta_{c} . P_{I P} / C_{I P}=10 \mathrm{~W} / \mathrm{Gbps}$ is the value proposed in section 3.1. The overhead factor $\eta_{c}$ will typically be 2 or less (for newer premises). 
Thus, we get for the power consumption in the routing layer (in [Watt]):

$$
P_{\text {routing }}=E_{I P} \cdot T_{I P}=\left(\eta_{c} \cdot \frac{P_{I P}}{C_{I P}}\right) \cdot\left(N_{d} \cdot \overline{D_{C}} \cdot 2 \cdot\left(1+\eta_{p r} \cdot H\right)\right)
$$

For the Ethernet, and OTN we deduce identically.

For the transponders and the optical switching devices we deduce identically, with the exception that we do not account for a long haul transponder at the access network sides.

For the OLAs we have (see Fig. 5):

$$
T_{C}=\eta_{p r} \cdot\left\lfloor\frac{\alpha}{L_{a m p}}\right\rfloor \cdot H \cdot D_{C}
$$

A fiber filling factor $f$ is added in the final equation of Eq. (4) to account for suboptimal usage of fiber channels. Note that we did not account for the booster and pre-amplifiers in equation (8), because we consider them to be part of the optical switching devices. However, if required they could be accounted for by slightly modifying equation (8) to:

$$
T_{C}=\eta_{p r} \cdot\left(2+\left\lfloor\frac{\alpha}{L_{a m p}}\right\rfloor\right) \cdot H \cdot D_{C}
$$

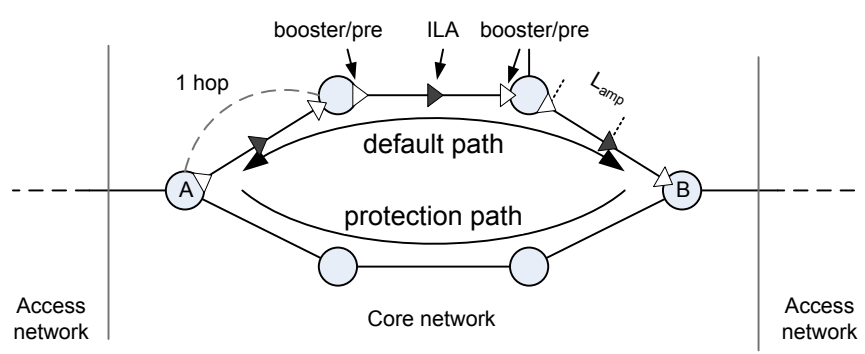

Fig. 5 Required optical line amplifiers for one $1+1$ protected demand

For the regeneration, the idea is identical to the OLAs. The number of regenerators per demand is approximated by the factor $\left\lfloor\frac{\alpha}{L_{\text {regen }}}\right\rfloor \cdot H$. However, if the link lengths $\alpha$ are in the same order of the regeneration length $\mathrm{L}_{\text {regen }}$ (taken to be $1500 \mathrm{~km}$ ), the approximation will be rather crude. An alternative approach would be to replace the earlier factor with a more general regeneration factor $\eta_{r}$ expressing the number of regenerations per demand, which could be estimated by a more accurate heuristic.

\subsection{Comparing with earlier analytical models}

It is useful to compare our model with the models in [11] and [12]. If we look at the power efficiency equation for the IP routing layer, given by equation (13) in [11] and the Table III Long Haul subnetwork $\mathrm{P}_{\mathrm{R}} / \mathrm{C}_{\mathrm{R}}$ term in [12], and in both cases ignoring the factor for future provisioning, these models have:
$E_{I P}=\eta_{c} \cdot \eta_{p r} \cdot(H+1) \cdot\left(\frac{P_{I P}}{C_{I P}}\right)$

However, our model has:

$E_{I P}=\eta_{c} \cdot 2 \cdot\left(\eta_{p r} \cdot H+1\right) \cdot\left(\frac{P_{I P}}{C_{I P}}\right)$

The apparent difference in factor 2 comes from the fact that the two earlier models consider unidirectional (i.e., halfduplex) demands but use a bidirectional $P_{I P} / C_{I P}$ value; as such the bidirectional value eliminates the factor 2 . We feel this is confusing, and thus consider both bidirectional (full-duplex) demands and efficiencies. The difference in application of the protection factor is because of a simplification by the existing models where the protection capacity is accounted both on the network side and the client side. For example, with $\eta_{p r}=2$ (e.g. for a $1+1$ protection scheme) the add/drop traffic is counted twice. In practice there will be only one add/drop port at the client side (see e.g. [19]), and is the approach we have taken in our model. So, the models are very similar, with the only difference being the protection scheme more accurately modeled in this work.

\section{EVALUATION AND CASE STUDY}

In this section, we show how the power consumption values listed in section 3 and the analytical power model from section 4 can be used to calculate the power consumption of a network. This also allows us to evaluate the analytical power consumption model.

\subsection{Cases considered}

We consider two different networks to which we apply a number of traffic matrices: the pan-European network and the American NSFNET network.

To calculate the power consumption associated with these demands, we use two different calculation methods (via simulation, and via the analytical hop count model), and in addition consider two separate scenarios (a router bypass scenario, and a non-bypass scenario).

In the next subsections, we provide more details on each of these cases.

\subsubsection{Network topologies}

We consider two different test networks (see Fig. 6) to calculate and evaluate the power consumption:

- the pan-European core network is based on the Géant research network [20], but has been modified to represent a commercial transport network (for example, to protect against single link failures, the topology has been modified so that each node is at least connected to two 
other nodes). We have used the DICONET pan-EU topology [21], which contains 34 nodes and 54 WDM links.

- $\quad$ NSFNET, a US network based on a former NSF network topology which has been used in many studies, e.g. [22]. It consists of 14 nodes and 21WDM links.

The network parameters are summarized in Table 6 .

(a) Pan-EU network

(b) NSFNET network
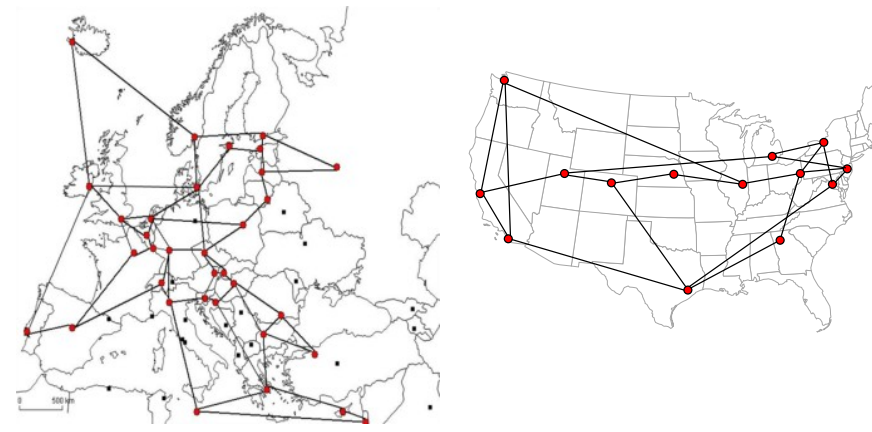

Fig. 6 IP topologies of the test networks

Table 6 Network topology parameters

\begin{tabular}{lll} 
Parameter & $\begin{array}{l}\text { Pan-European } \\
\text { network }\end{array}$ & NSFNET \\
Number of nodes & 34 & 14 \\
Number of links & 54 & 21 \\
Average node degree & 3.09 & 3 \\
Average link length & $753 \mathrm{~km}$ & $1083 \mathrm{~km}$ \\
Minimum link length & $67 \mathrm{~km}$ & $260 \mathrm{~km}$ \\
Maximum link length & $2361 \mathrm{~km}$ & $2840 \mathrm{~km}$ \\
\hline
\end{tabular}

\subsubsection{Network traffic demands}

For our case study and evaluation, we apply various traffic matrices, summarized in Table 7.

For the pan-EU network we consider: (a) a gravity traffic matrix where nearby nodes have larger demands, thus closer resembling real life demands [21], (b) a random fully-meshed traffic matrix, and (c) a uniform fully-meshed traffic matrix where all demands are equal.

For NSFNET we only consider a random fully-meshed traffic matrix.

In all the cases above, we scale up the traffic demands, so that we load the network with 10 different traffic matrices ranging from 2.5 to 100 Gbps of average traffic demand.
Table 7 Traffic matrices

\begin{tabular}{lllll}
\hline Parameter & $\begin{array}{l}\text { Pan-EU, } \\
\text { gravity } \\
367\end{array}$ & $\begin{array}{l}\text { Pan-EU, } \\
\text { random } \\
561\end{array}$ & $\begin{array}{l}\text { Pan-EU, } \\
\text { uniform } \\
561\end{array}$ & $\begin{array}{l}\text { NSFNET, } \\
\text { random } \\
91\end{array}$ \\
$\begin{array}{l}\text { Number of } \\
\begin{array}{l}\text { IP/MPLS } \\
\text { demands }\end{array}\end{array}$ & 4.6 & 4.6 & 2.9 \\
$\begin{array}{l}\text { Actual hop count } \\
\text { (by simulation, } \\
\text { see section 5.1.4) }\end{array}$ & 4.1 & 3.83 & 3.83 & 2.45 \\
$\begin{array}{l}\text { Estimated hop } \\
\text { count (see section } \\
5.1 .4)\end{array}$ & 3.83 & & & \\
\hline
\end{tabular}

\subsubsection{Node architecture and (non-)bypass scenarios}

For both networks, we consider the architectural setup shown in Fig. 7. Other architectures are possible, e.g. IP-over-OTNover-WDM see e.g. [6].

In the IP/MPLS layer, a core router is equipped with line cards, providing short reach interfaces. The granularity for the interfaces differs: the access or client-side traffic connects to the router using $1 \mathrm{Gbps}$ interfaces, the core network side channel interfaces are all $10 \mathrm{Gbps}$ interfaces. Note that, depending on the demand capacity, one or more interfaces will be required per demand.

In the WDM layer, long reach transponders provide a DWDM optical signal, which is switched using an optical cross connect (OXC) to the correct link. A mux/demux aggregates up to 40 channels on a fiber. For each link, we assume an unlimited numbers of fibers to be available. A booster and pre-amplifier amplify all signals in a fiber pair respectively upon leaving or entering a node. An inline amplifier is placed every $80 \mathrm{~km}$. For link lengths longer than the regenerator span, taken to be $1500 \mathrm{~km}$, the signal is switched by the OXC to pass through a regenerator. The regenerator itself is composed of 2 back-to-back transponders.

These architectural assumptions are summarized in Table 8.

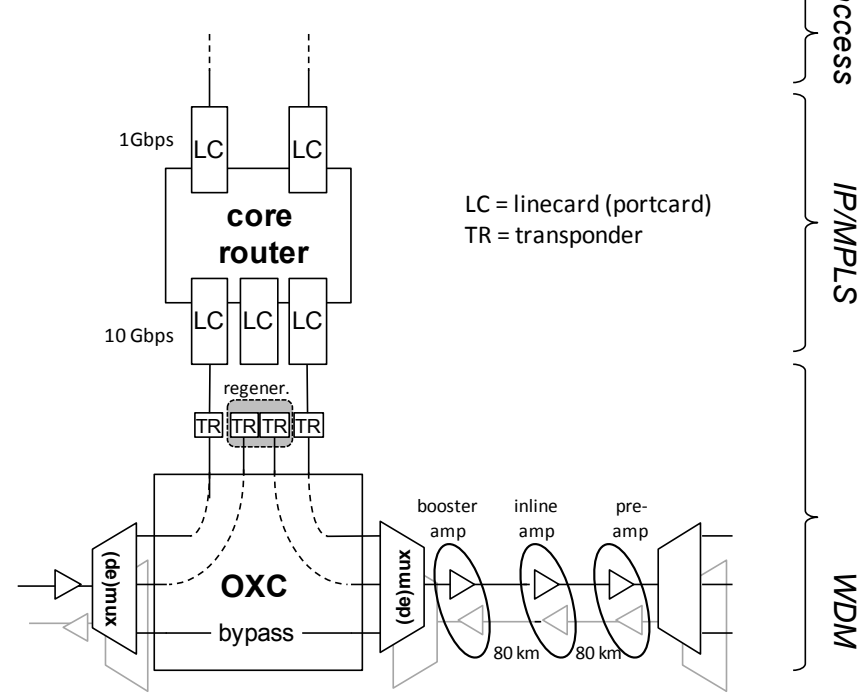

Fig. 7 Network node and link architecture 
With this architecture in mind, we consider two different scenarios for calculating the power consumption:

- A non-bypass scenario, where all traffic in the node both the traffic that starts or ends in the node, as well as the transit (bypass) traffic - is processed by the core router. This provides opportunity for the IP router to groom - i.e., bundle traffic demands from different sources destined for the same outgoing link. This assures that optical channels can be optimally filled.

- An optical bypass scenario, where a dedicated lightpath (channel) is set up from source node to destination node. By doing so, we create a new, modified IP topology which we call the virtual topology. This way, the transit (bypass) traffic destined for another node does not have to be handled by the IP router, and consequently not have to be converted from the optical to the electronic domain and back to the optical domain. On the other hand, if a source-destination traffic demand is smaller than the available channel capacity, the channel will not be optimally used, resulting in a higher number of channels and equipment required. Note that our optical bypass scenario is the extreme case of applying optical bypass. More intermediate cases would consist of optical multihop bypass.

Furthermore, we assume that the network provides $1+1$ protection, which means that for each demand two linkdisjoint IP connections or lightpaths are set up. If one path fails, the traffic is still available without interruption over the other path.

Table 8 Network architectural parameters

\begin{tabular}{ll}
\hline Parameter & Value \\
Optical amplification span $\mathrm{L}_{\mathrm{amp}}$ & $80 \mathrm{~km}$ \\
Regenerator span $\mathrm{L}_{\text {regen }}$ & $1500 \mathrm{~km}$ \\
Channels per fiber & 40 \\
Channel capacity & $10 \mathrm{Gbps}$ \\
Protection & $1+1$ \\
Node client-side capacity interface granularity & $1 \mathrm{Gbps}$ \\
Node network-side capacity interface granularity & $10 \mathrm{Gbps}$ \\
\hline
\end{tabular}

\subsubsection{Calculation methods}

We use two different methods to calculate the power consumption in the networks, of which we then compare the resulting values. In both cases, we assume a PUE of 2 .

\section{Using simulation to dimension the network}

The first method is based on dimensioning the network via simulation, that is, calculating for each traffic demand the path that will be followed across all nodes, and subsequently determine the equipment required. By multiplying the equipment count with its respective power consumption, the total power is determined.

We route the demands using a shortest cycle algorithm (to provide $1+1$ protection) and wavelengths are selected following a first-fit wavelength assignment algorithm [23]. The power values used are summarized in Table 9. For all components we use the power values listed in section 3 . Because of simulation tool constraints we generalized on the OXC power consumption and calculate an average OXC power consumption value based on the average node degree of the network (see Table 6).

Table 9 Dimensioning via simulation power values

\begin{tabular}{lll}
\hline Parameter & Value & Unit \\
IP router efficiency & 10 & W/Gbps \\
Transponder $(10 \mathrm{G}$, bidirectional) & 50 & $\mathrm{~W}$ \\
$\begin{array}{l}\text { Regenerator }(10 \mathrm{G}, \text { per bidirectional } \\
\quad \text { channel) }\end{array}$ & 100 & $\mathrm{~W}$ \\
$\begin{array}{l}\text { OLA, long span } 80 \mathrm{~km} \\
\text { OXC, average node degree } \bar{d}, \text { with }\end{array}$ & 110 & $\mathrm{~W}$ \\
$\quad(\bar{d} \cdot 135+150)$ & $\mathrm{W}$ \\
$\begin{array}{l}\text { add/drop degree } a=d \\
\text { Power usage effectiveness (PUE) }\end{array}$ & 2 & \\
\hline
\end{tabular}

\section{Using the analytical power model}

The second method uses the analytical power model proposed in section 4. This is less accurate than the simulation approach, but has the advantage of being trivial to compute, as it only requires filling in the parameters in the equations.

The values used are listed in Table 10.

Table 10 Analytical power model values

\begin{tabular}{|c|c|c|c|}
\hline Parameter & Symbol & $\begin{array}{l}\text { Value } \\
\text { (non- } \\
\text { bypass) }\end{array}$ & $\begin{array}{l}\text { Value } \\
\text { (bypass) }\end{array}$ \\
\hline IP router efficiency & $\mathrm{P}_{\mathrm{IP}} / \mathrm{C}_{\mathrm{IP}}$ & \multicolumn{2}{|c|}{$10 \mathrm{~W} / \mathrm{Gbps}$} \\
\hline Transponder efficiency (10G) & $\mathrm{P}_{\mathrm{TR}} / \mathrm{C}_{\mathrm{TR}}$ & \multicolumn{2}{|c|}{$5 \mathrm{~W} / \mathrm{Gbps}$} \\
\hline Regenerator efficiency (10G) & $\mathrm{P}_{\mathrm{RE}} / \mathrm{C}_{\mathrm{RE}}$ & \multicolumn{2}{|c|}{$10 \mathrm{~W} / \mathrm{Gbps}$} \\
\hline OLA efficiency & $\mathrm{P}_{\mathrm{OLA}} / \mathrm{C}_{\mathrm{OLA}}$ & \multicolumn{2}{|c|}{$0.27 \mathrm{~W} / \mathrm{Gbps}$} \\
\hline $\begin{array}{l}\text { OXC efficiency (40 10G- } \\
\text { channels) }\end{array}$ & $\mathrm{P}_{\mathrm{OXC}} / \mathrm{C}_{\mathrm{OXC}}$ & \multicolumn{2}{|c|}{$0.46 \mathrm{~W} / \mathrm{Gbps}$} \\
\hline Average IP/MPLS hop count & $\mathrm{H}$ & see text & 1 \\
\hline $\begin{array}{l}\text { Average hop count optical } \\
\text { switching }\end{array}$ & $H^{\prime}$ & \multicolumn{2}{|c|}{ see text } \\
\hline $\begin{array}{l}\text { Provisioning factor for } \\
\text { protection }\end{array}$ & $\eta_{\mathrm{pr}}$ & \multicolumn{2}{|c|}{2} \\
\hline $\begin{array}{l}\text { Provisioning factor for cooling } \\
\text { (PUE) }\end{array}$ & $\eta_{\mathrm{C}}$ & \multicolumn{2}{|c|}{2} \\
\hline Number of IP/MPLS demands & $\mathrm{N}_{\mathrm{d}}$ & \multirow{2}{*}{\multicolumn{2}{|c|}{$\begin{array}{l}\text { see text } \\
\text { see text }\end{array}$}} \\
\hline Average demand capacity & $\overline{D_{C}}$ & & \\
\hline $\begin{array}{l}\text { Average fiber filling (\% of } \\
\text { used channels in fiber) }\end{array}$ & $\mathrm{f}$ & \multicolumn{2}{|c|}{$100 \%$} \\
\hline Average (lightpath) link length & $\alpha$ & see text & see text \\
\hline
\end{tabular}

The parameter values were determined as follows:

- The IP core router, transponder, regenerator and amplifier efficiency values are as earlier defined.

- The $O X C$ efficiency $\mathrm{P}_{\mathrm{OXC}} / \mathrm{C}_{\mathrm{OXC}}$ for one demand is approximated by the $\mathrm{OXC}$ power consumption for the average node degree $\bar{d}$, divided by the total capacity of the OXC. Thus, for our 40-channel OXC, we get:

$$
\frac{P_{O X C}}{C_{O X C}}=\frac{(150[W]+\bar{d} \cdot(85[W]+50[W]))}{40 \cdot 10[G b p s] \cdot \bar{d}}
$$

For the pan-European and NSFNET network, the average node degree $\bar{d}$ is 3.09 and 3 respectively (see Table 6). 
Thus, the value for both networks is almost identical, and approximates to $0.46 \mathrm{~W} / \mathrm{Gbps}$, in line with Table 5 .

- Following the network global expectation model proposed in [7], the hop count $H$ in a uniform network can be approximated by the following equation, with $\mathrm{N}$ the total number of nodes in the network and $\mathrm{L}$ the number of bidirectional links in the network:

$$
H=\sqrt{\frac{N-2}{\frac{2 L}{N}-1}}
$$

For the non-bypass scenario, for the pan-European network we have $\mathrm{N}=34$ and $\mathrm{L}=54$, which gives $\mathrm{H}=3.83$, whereas for the considered traffic demands routed by the shortest cycle algorithm as described above, the hop count is 4.1 and 4.6 (see Table 7). As our analytical power model scales linearly with the hop count, the error on the result will be equally large. As such, to evaluate the proposed power model fairly, we will use the actual hop count as determined by dimensioning the network via simulation with a given traffic matrix. These values are listed in Table 7, both for the pan-EU network and NSFNET.

For the bypass scenario the hop count $\mathrm{H}$ is 1 , as we have created a new virtual IP topology where direct sourcedestination lightpaths are set up. However, the hop count for the optical switching $H^{\prime}$, remains identical to the nonbypass scenario hop count, as each connection traverses an OXC regardless of the scenario.

- The number of demands is directly available from the traffic matrix, as well as the average demand capacity.

- The average fiber filling is estimated to be $100 \%$, which will be a good approximation for large demands.

- $\quad$ The average (lightpath) link length is given directly by the network topology (see Table 6). Again, it could also be estimated; the network global expectation model [7] provides an approximation based on the geographic area $A$ covered by the network $\alpha=\sqrt{\mathrm{A}} /(\sqrt{\mathrm{N}}-1)$. For an estimated area of the pan-European network of $3000 \times 3300 \mathrm{~km}^{2}$, this would give $\alpha=653 \mathrm{~km}$, which gives only a $13 \%$ difference from the actual value of $753 \mathrm{~km}$.

As for the bypass scenario we have a hop count equal to one, the lightpath link length equals the sum of lengths of all the fibers that the lightpath is traversing.

\subsection{Results}

\subsubsection{Model evaluation}

Fig. 8 shows the result of applying the various traffic matrices (section 5.1.2) to the pan-EU and NSFNET networks. The charts map the power consumption with average traffic demand increasing to up to ten times the channel and port capacity (10 Gbps). The solid lines represent the power consumptions as calculated by the simulation approach. The dashed lines indicate the result from the analytical power model. The upper lines are the power consumption for the non-bypass scenario, while the lower lines are for the optical bypass scenario.

We make the following observations:

- The analytical power model approaches very well the simulation result (Fig. 8). In the non-bypass scenario, for high demands (relative to the channel capacity) the approximation converges to $97 \%$ for the pan-EU network and $93 \%$ for NSFNET. Note that, as explained in section 5.1.4, part of this good approximation is because we used the actual hop count value in our analytical model, as determined through simulation, instead of a heuristic to approximate it.

- The estimation is very good for all layers except the regeneration (Fig. 9). This is the result of the crude approximation made for the number of regenerations per demand (see section 4.2). For the non-bypass scenario the mathematical flooring of the average link length over the regeneration length gives zero, resulting in zero power for the regeneration. On the other hand, for the bypass scenario, the regeneration estimate is too high.

- The crude regeneration estimation is also the reason for the NSFNET approximation to be lower than the pan-EU approximation. As the total power consumption for NSFNET is much lower (because of the lower number of nodes, and thus demands, for an equal average traffic demand), and because of the longer link lengths (see Table 6), the influence of the regeneration estimation error is relatively larger, see Fig. 9 (c) and (d).

- For the optical bypass scenario the approximation is good for high demands. However, it does fall short for low demands, as clearly shown in Fig. 10. This is no surprise, as for traffic demands below the network interface capacity (i.e., below $10 \mathrm{Gpbs}$ ) the model does not take into account the suboptimal used interfaces, thereby overestimating the router efficiency; the underestimation is much worse than for the non-bypass scenario because in the latter the grooming dampens the sub-optimality. 
(a) pan-EU (gravity demands)

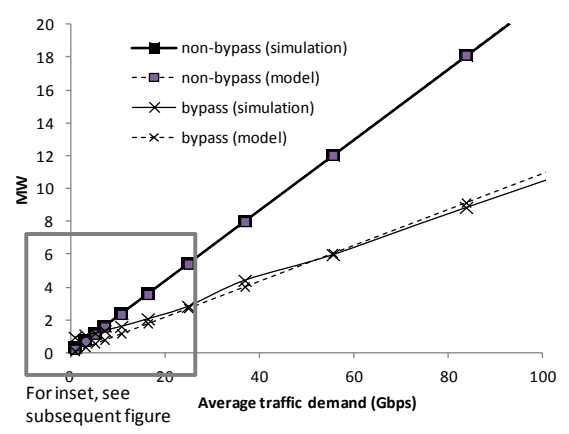

(c) Pan-EU (uniform demands)

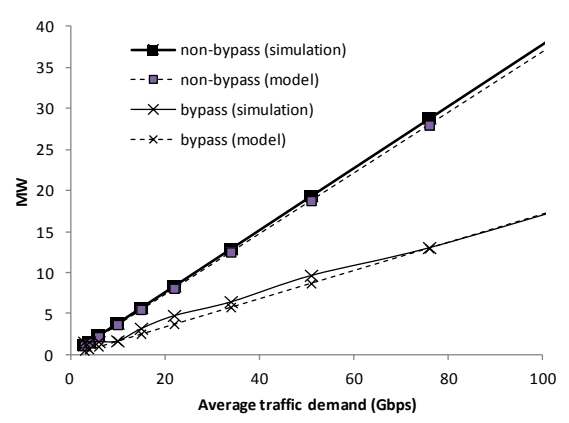

(b) Pan-EU (random demands)

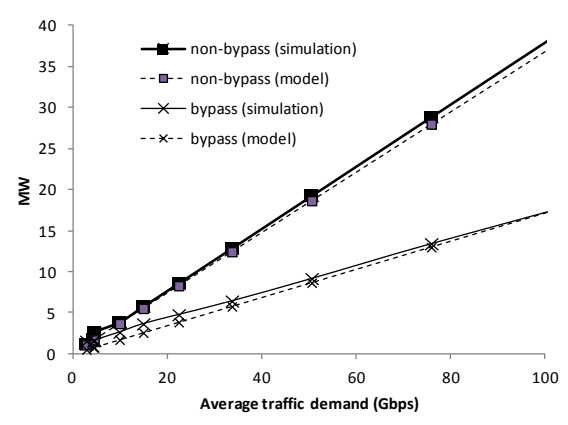

(d) NSFNET (random demands)

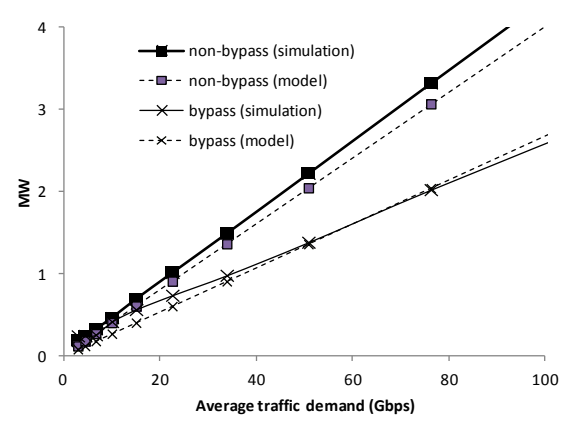

Fig. 8 Power consumption with increasing traffic demands (gravity, random and uniform) for the pan-EU and NSFNET network.

(a) Pan-EU, gravity matrix, non-bypass

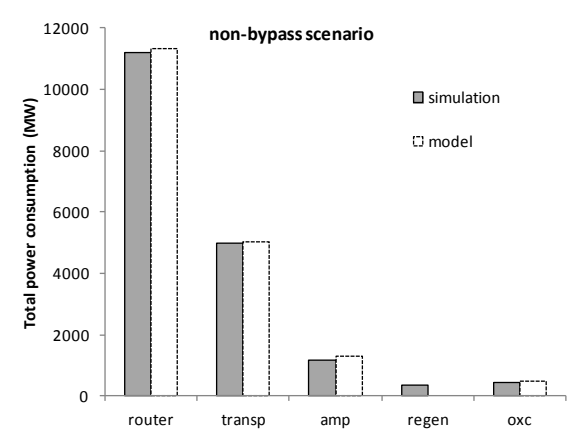

(c) NSFNET, random matrix, non-bypass

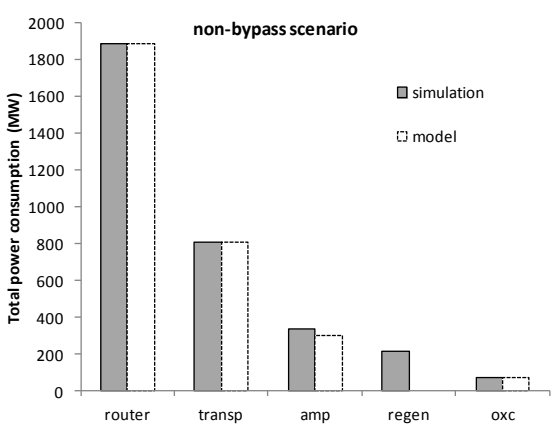

(b) Pan-EU, gravity matrix, bypass

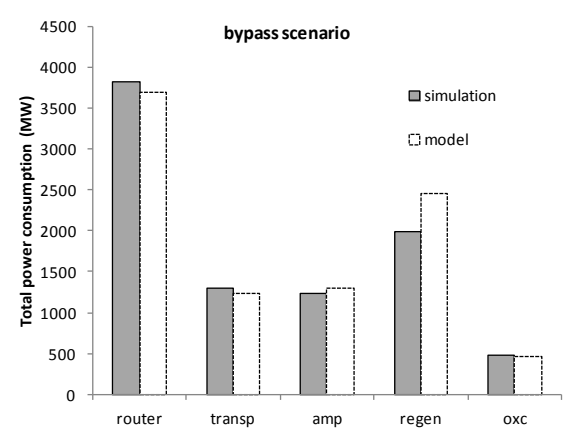

(d) NSFNET, random matrix, bypass

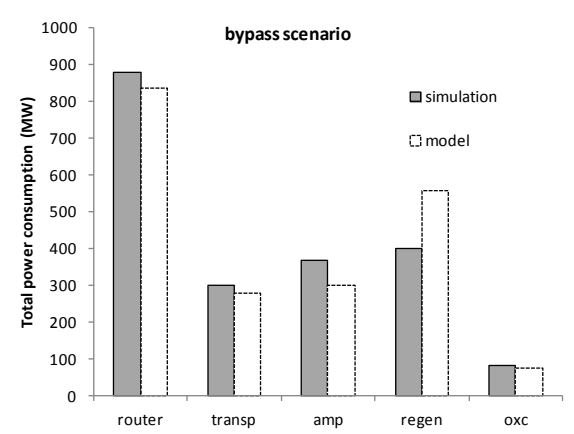

Fig. 9 Comparison of the component power consumptions as calculated by the simulation approach (grey bars), and the power model approach (white bars). Average traffic demand equals 80 Gbps for all cases. 


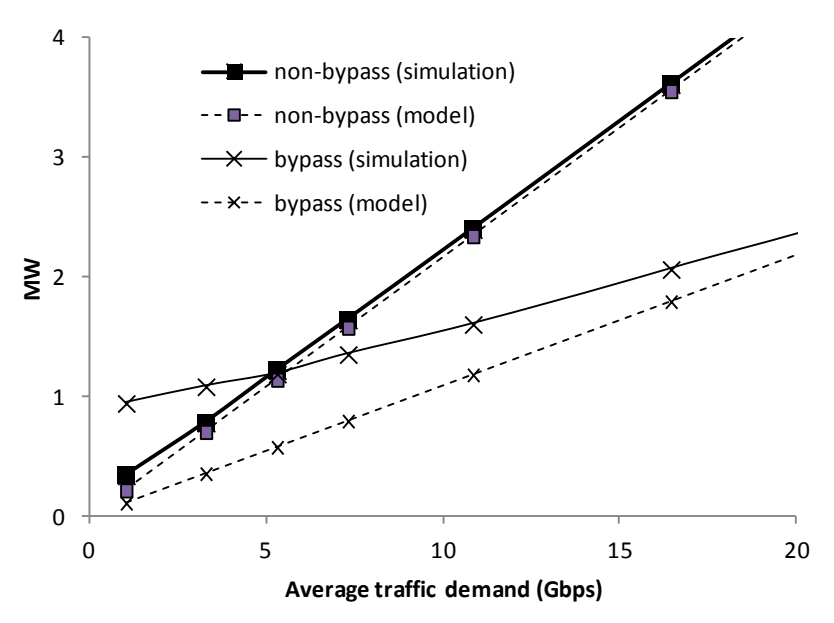

Fig. 10 Detail of inset in Fig. 8

\subsubsection{Component power consumption distribution}

If we look more in detail to the distribution over the different components (Fig. 11), we see that the largest share of power consumption is concentrated in the IP router. The transponders are the second major contributor. This follows also directly from the difference in efficiency (for $10 \mathrm{G}$ equipment, we defined $P_{R} / C_{R}$ to be the double of $P_{T R} / C_{T R}$, see Table 5). This is also in line with earlier findings such as in [3], however, the figures differ slightly. For example, [3] attributes $90 \%$ to the routers and $5 \%$ to the transponders. This is due to the very high power consumption $(1000 \mathrm{~W})$ assumed for an IP router port.

Amplification and regeneration power consumption only becomes relevant in the bypass scenario. For the amplifiers this is only because of the reduction of the total power consumption, as the absolute amplifier power consumption remains constant; for the regenerations this relative increase is in addition caused by the longer link lengths, see section 5.1.4.

Fig. 12 shows that indeed the IP router and transponder power consumption has decreased for the bypass scenario, and that the amplifier and OXC power consumption remains the same in both scenarios. A lot of skipped router hops were replaced by regenerator hops, which is shown in the increased regeneration power consumption.

The OXC power consumption is negligible in both scenarios.

While Fig. 11 and Fig. 12 show only the case for the pan-EU network with gravity demands, the results for the 3 other cases are very similar. The longer link lengths in the NSFNET slightly increase the relative contribution of the amplifier and regeneration power consumption . (a) Non-bypass scenario

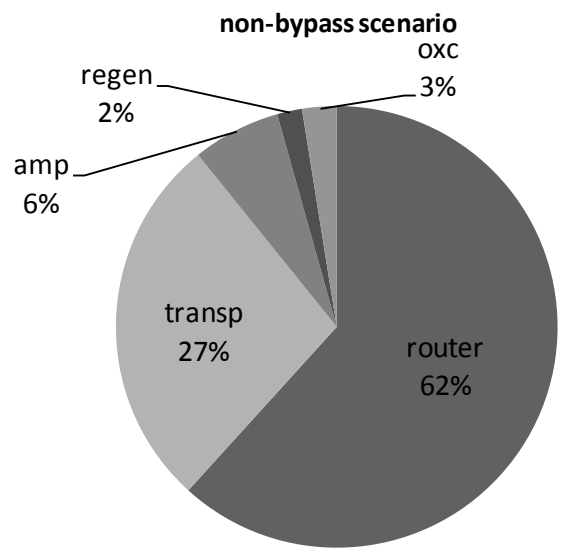

(b) Bypass scenario

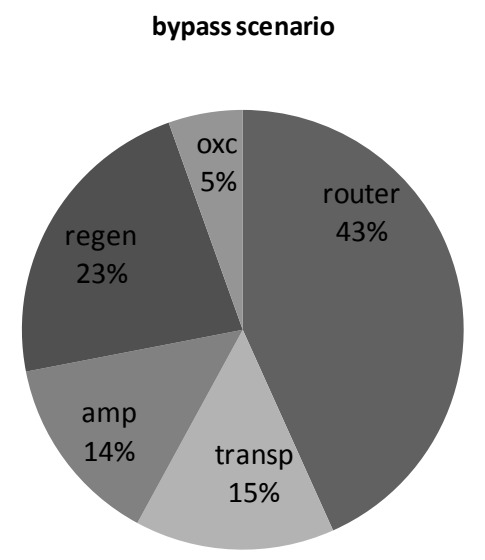

Fig. 11 Relative component power consumption for the pan-EU network at $80 \mathrm{Gbps}$ average demand (simulation results) 


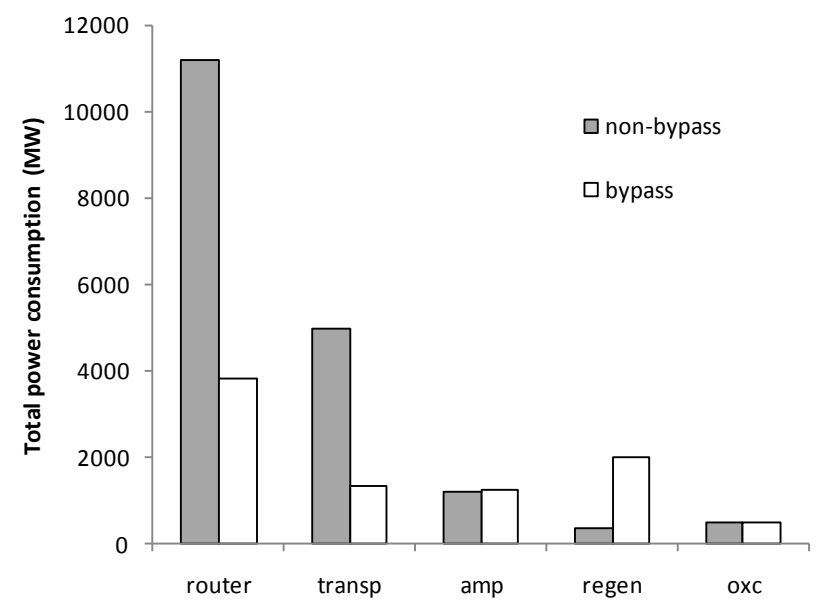

Fig. 12 Component power consumption for the pan-EU network (gravity matrix, 80 Gbps)

\subsubsection{Savings from optical bypass}

As already shown in earlier figures, the optical bypass scenario clearly provides potential for significant power savings over the non-bypass scenario, but not under all circumstances. In Fig. 13 the relative savings of the bypass scenario over the non-bypass scenario for the pan-EU network are mapped.

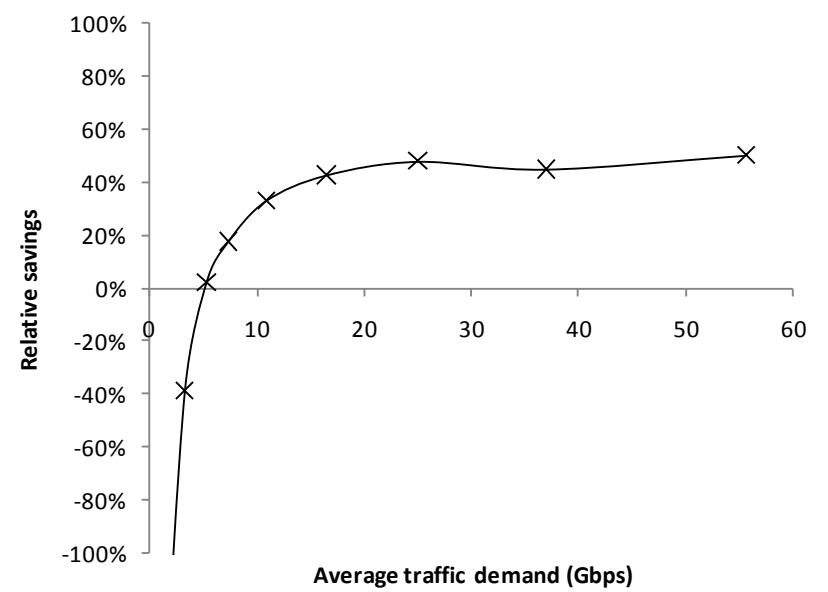

Fig. 13 Relative savings of bypass over non-bypass (pan-EU network, gravity matrix)

For low demands savings are negative, i.e. optical bypass consumes more energy. This is because for optical bypass, at least one dedicated optical channel is required for each source-destination demand. As at the network side we only have $10 \mathrm{Gbps}$ interfaces available, for demands below 10 Gbps the channels are not optimally filled. This is less the case for the non-bypass scenario where all the traffic is 'pulled' up into the IP routing layer: the router can groom all traffic demands for the same outgoing links, thereby optimally filling the channels, saving on the number of $10 \mathrm{Gbps}$ interfaces and subsequently power consumption.
With rising traffic demands (from around 4 Gbps of average traffic demand), the bypass strategy starts to pay off, consuming less energy. The power consumption of the bypass strategy initially rises slower than for the non-bypass strategy (see also Fig. 10). This is because the underutilized $10 \mathrm{Gbps}$ channels can carry the additional traffic demands at almost no energy increase, whereas for the non-bypass this is not the case.

For high demands - i.e. higher than the channel and interface capacity, which is $10 \mathrm{Gbps}$ - savings converge to about $50 \%$. The slight drop around $37 \mathrm{Gbps}$ is because of the coincidental large number of $11 \mathrm{Gbps}$ demands in the traffic matrix, which in the bypass scenario results in one of the two required channels being suboptimally filled. It is important to point out that the $50 \%$ value is no magic number. As shown in [3], the maximum energy savings achieved depend on the size of the network (in terms of nodes). For a network with similar connectivity, gains will be lower for smaller networks, and higher for larger networks. This is because for larger networks the chance of establishing longer lightpaths increases, bypassing more intermediate nodes, and thus saving on router interfaces. This is confirmed by our findings, which indicate that for the NSFNET network (only 14 nodes, with the pan-EU network having 34 nodes) the savings converge to around $40 \%$.

\section{Conclusions}

This paper has two main objectives: (a) provide traceable and well-defined power consumption estimates for optical multilayer network equipment, and (b) provide an analytical power consumption model that avoids the need for network dimensioning, for example via simulation.

The equipment power consumption values are defined for reference in Table 1, Table 2, Table 3 and Table 4. They represent typical values (as opposed to maximum power consumption values), include chassis and controller overhead, and are for bidirectional (full-duplex) equipment and traffic. We note that our values for optical amplifiers are typically higher than values used in earlier academic works. In contrast, our IP router power consumption values are typically lower, partly due to technical advances in power efficiency. All values are best-effort representations for the current situation. Suggestions for extrapolations to future values and efficiencies are mentioned in e.g. [12].

The analytical power model we propose is mainly based on the average hop count and aligns nicely with earlier work such as [11] and [12]. It provides a good approximation to the power consumption obtained by simulation, if the hop count is correctly determined or estimated, and if the equipment capacity (interfaces, channels, ...) is not over-provisioned for the actual demands (e.g. when employing optical bypass). As such, research into more accurate hop count estimation for a given network, traffic demand pattern and routing policy 
would be useful. The estimation for the regeneration power consumption is less accurate, and would also benefit from a more accurate heuristic to estimate the amount of regenerations per demand.

Our analysis confirms that for current networks the main share of the power consumption - in the order of $60 \%$ - is in the IP/MPLS layer, although we found the share to be less than in earlier publications. Transponders are second in power consumption, in the order of a fifth or a quarter of the total power consumption. OXC power consumption is currently negligible.

Optical bypass is a valuable technique to save power, in our exemplary network up to $50 \%$. Savings however depend on the size of the network, and require optimally used interfaces.

\section{ACKNOWLEDGMENTS}

The authors would like to thank the STRONGEST and TREND members for their valuable feedback and input. The work described in this paper was carried out with the support of the BONE project (Building the Future Optical Network in Europe) and the TREND project (Towards Real Energyefficient Network Design), both a Network of Excellence funded by the European Community's Seventh Framework; the IBBT-project GreenICT and the STRONGEST project funded by the European Community's Seventh Framework Programme FP7/2007-2013 under grant agreement n 247674.

\section{REFERENCES}

[1] M. Gupta and S. Singh, Greening of the Internet Proceedings of the 2003 conference on Applications, technologies, architectures, and protocols for computer communications - SIGCOMM '03, p. 19-26, Karlsruhe, Germany, 2003, doi : 10.1145/863955.863959

[2] SMART 2020: Enabling the low carbon economy in the information age. 2008, pp. 1-87

[3] G. Shen and R. S. Tucker, Energy-minimized design for IP over WDM networks, Journal of Optical Communications and Networking, Vol. 1, No. 1, pp. 176-186, June 2009, doi : 10.1364/JOCN.1.000176

[4] L. Chiaraviglio, M. Mellia and F. Neri, Energy-aware Backbone Networks: a Case Study, IEEE Communications Workshops, 2009, doi : $10.1109 /$ ICCW.2009.5208038

[5] Van Heddeghem, W., Idzikowski, F.: Equipment power consumption in optical multilayer networks - source data, Technical Report IBCN12-001-01 (January 2012), available at http://powerlib.intec.ugent.be

[6] R. Huelsermann, M. Gunkel, C. Meusburger, and D. A. Schupke; Cost modeling and evaluation of capital expenditures in optical multilayer networks; Journal of Optical Networking; Vol. 1, No. 9, pp. 814-833, September 2008, doi : 10.1364/JON.7.000814

[7] S. K. Korotky, Network global expectation model: A statistical formalism for quickly quantifying network needs and costs, Journal of Lightwave Technology, Vol. 22, No. 3, pp. 703-722, 2004, doi : $10.1109 /$ JLT.2004.825756

[8] W. Van Heddeghem, M. De Groote, W. Vereecken, D. Colle, M Pickavet, and P. Demeester, Energy-Efficiency in Telecommunications Networks: Link-by-Link versus End-to-End Grooming, ONDM 2010, Kyoto (Japan): 2010, doi : 10.1109/ONDM.2010.5431570
[9] C. Dorize, A. Morea, O. Rival, B. and Berde, An energy-efficient node interface for optical core networks, ICTON, Munich, Gemrany, 2010, doi : 10.1109/ICTON.2010.5549142

[10] J. Chabarek et.al., Power Awareness in Network Design and Routing, INFOCOM 2008, pp. 457-465, doi : 10.1109/INFOCOM. 2008.93

[11] J. Baliga, R. Ayre, K. Hinton, W. Sorin, and R. S. Tucker, Energy consumption in optical IP networks, Journal of Lightwave Technology, Vol. 27, No. 13, pp. 2391-2403, July 2009, doi : 10.1109/JLT.2008.2010142

[12] D. Kilper, G Atkinson, and K. Korotky, Power Trends in Communication Networks, Journal of Selected Topics in Quantum Electronics, Vol. 17, No. 2, pp. 275-284, March/April 2011. doi : 10.1109/JSTQE.2010.2074187

[13] F. Idzikowski, Power Consumption of network elements in IP over WDM networks, Technische Universität Berlin, Telecommunication Networks Group, TKN Technical Report TKN-09-006, July 2009

[14] S. Aleksić, Analysis of Power Consumption in Future High-Capacity Network Nodes, Journal of Optical Communications and Networking (JOCN), vol. 1, 2009, pp. 245-258, doi : 10.1364/JOCN.1.000245

[15] O. Tamm, C. Hermsmeyer, and Allen M. Rush, Eco-Sustainable System and Network Architectures for Future Transport Networks, Bell Labs Technical Journal 14 94), pp 311-328, 2010, doi : $10.1002 /$ b7tj.20418

[16] B. Mukherjee, Optical WDM Networks, Springer, 2006, ISBN: 978-0387-29055-3

[17] C. Belady, A. Rawson, J. Pfleuger, and T. Cader, Green grid data center power efficiency metrics: PUE and DCIE, (white paper), 2008.

[18] U.S. Environmental Protection Agency, Report to Congress on Server and Data Center Energy Efficiency, 2007,

http://www.energystar.gov/ia/partners/prod_development /down 1oads/EPA_Datacenter_Report_Congress_Fina11.pdf.

[19] D. Martin, 1:1 Protection Switching overview, IEEE 802.1, presentation July 16-19 2077, San Francisco, available from http://www. i eee802.org/1/files/pub1ic/docs2007/aymartin-protection-0707-v01.pdf

[20] Géant, The Géant network, http://www.geant.net/Network/NetworkTopology

[21] DICONET, European ICT-research project, http://www.diconet.eu.

[22] R. Huelsermann, S. Bodamer, M. Barry, A. Betker, C. Gauger, M. Jäger, M. Köhn, and J. Späth , A set of typical transport network scenarios for network modelling, ITG FACHBERICHT, pp. 65-72, 2004

http: //www.ikr.uni-

stuttgart.de/Content/Publications/Archive/Ko_ITGPhotNe tze04_36322.pdf

[23] H. U. I. Zang, A Review of Routing and Wavelength Assignment Approaches for Wavelength-Routed Optical WDM Networks, Optical Networks Magazine, Vol. 1 No.1, pp. 47-60, Jan. 2000 